\title{
Latin American Society for Pediatric Research (LASPR) Selected Abstracts From the LII Annual Meeting
}

\author{
Paracas, Perú \\ November 02-06, 2014 \\ Julio Marin (Perú), President \\ Giuseppe Grandy (Bolivia), President Elect \\ Marta Sanabria (Paraguay), General Secretary
}

Sponsorship Statement

The publication of the selected meeting abstracts was funded by the Latin American Society for Pediatric Research to promote development across disciplines and to improve pediatric care in the region (http://www.slaip.org.ar).

doi:10.1038/pr.2015.30

BIOAVAILABILITY OF INCREASED DOSES OF IRON IN THE PRESENCE OF CALCIUM AND ZINC

Pizarro F, Kreindl C, Olivares M, Brito A, Arredondo M

Instituto de Nutrición y Tecnología de los Alimentos (INTA), Universidad de Chile, Santiago, Chile

Background: We have previously reported that supplementation of $800 \mathrm{mg}$ of calcium $(\mathrm{Ca})$ does not inhibit the absorption of iron $(\mathrm{Fe})$. The role of zinc $(\mathrm{Zn})$ on iron bioavailability in the presence of $\mathrm{Ca}$ is unknown.

Objective: To determine the effect of $10 \mathrm{mg}$ and $20 \mathrm{mg}$ of $\mathrm{Zn}$ on the bioavailability of 5, 10, 20, or $30 \mathrm{mg}$ Fe and $650 \mathrm{mg}$ of $\mathrm{Ca}$.

Methods: The study was conducted in two groups of 14 healthy adult women. Group A: on days 1, 2, 14 , and 15 , subjects ingested $5,10,20$, or $30 \mathrm{mg}$ of $\mathrm{Fe}\left(\mathrm{FeSO}_{4}\right)$, labeled with ${ }^{55} \mathrm{Fe}$ or ${ }^{59} \mathrm{Fe}$, plus $650 \mathrm{mg}$ of $\mathrm{Ca}\left(\mathrm{CaCl}_{2}\right)$ and $10 \mathrm{mg} \mathrm{Zn}\left(\mathrm{ZnSO}_{4}\right)$. Group $\mathrm{B}$ consumed equal amounts of $\mathrm{Fe}$ and $\mathrm{Ca}$, but ingested $20 \mathrm{mg}$ of $\mathrm{Zn}$. At 14 and $28 \mathrm{~d}$, blood samples were obtained to determine both iron bioavailability and iron status. Two-way ANOVA for repeated measures was used.

Results: Group A presented geometric means and range \pm 1 SD of bioavailability: 9.9\% (5.2-18.7), $7.4 \%(4.0-13.6), 9.9 \%(5.8-16.9)$, and $6.5 \%$ (3.3-13.1) for 5, 10, 20, and $30 \mathrm{mg}$ of Fe plus $650 \mathrm{mg}$ $\mathrm{Ca}$ and $10 \mathrm{mg} \mathrm{Zn}$, respectively. In Group B bioavailability was 10.0\% (4.1-24.7), 11.0\% (5.7-20.9), $12.1 \%(6.8-21.5)$, and $9.8 \%(5.8-16.3)$, respectively for the same concentrations and $20 \mathrm{mg}$ of $Z \mathrm{n}$. No significant differences were observed when comparing Fe bioavailability fractions of $5 \mathrm{mg}, 10$, 20 , and $30 \mathrm{mg}$ bioavailability of Fe in groups A and B.

Conclusion: Supplementation of $650 \mathrm{mg}$ of $\mathrm{Ca}$ and 10 or $20 \mathrm{mg}$ of $\mathrm{Zn}$ did not affect the bioavailability of 5, 10, 20, and $30 \mathrm{mg}$ of $\mathrm{Fe}$.

Funding: FONDECYT-1130090

\section{2}

EFFECT OF DAILY SUPPLEMENTATION WITH IRON AND ZINC ON IRON STATUS: A RANDOMIZED DOUBLE-BLIND, PLACEBO-CONTROLLED TRIAL

Olivares M, Mujica-Coopman MF, Borja A, Pizarro F

Instituto de Nutrición y Tecnología de los Alimentos (INTA), Universidad de Chile, Santiago, Chile

Objective: To determine the effect of daily supplementation with $30 \mathrm{mg}$ of iron (Fe) plus $30 \mathrm{mg}$ of zinc $(\mathrm{Zn})$ on Fe status of women of childbearing age.

Methods: This was a randomized, double-blind, placebo-controlled trial. Eighty-one women (18$45 \mathrm{y}$ old) were randomly assigned to receive either a daily single dose of $30 \mathrm{mg}$ de Fe (Group $1 ; n=$ 28), $30 \mathrm{mg}$ of Fe plus $30 \mathrm{mg}$ of $\mathrm{Zn}$ (Group 2; $n=26$ ), or placebo $(n=27)$ for $3 \mathrm{mo}$. Hemoglobin (Hb), mean corpuscular volume, serum $\mathrm{Fe}$, total iron binding capacity, transferrin saturation, erythrocyte Zn protoporphyrin, serum ferritin (SF), serum transferrin receptor (TfRs), total body Fe, serum Zn and high sensitivity $\mathrm{C}$ reactive protein were measured at baseline and at end of the study.

Results: At baseline 3.7, 28, and 26\% of women had iron deficiency anemia (IDA), Fe deficiency without anemia and depleted Fe stores, respectively. No significant differences on Fe status were found between groups before and after supplementation. After supplementation, group 2 showed a significant increase of $\mathrm{Hb}$ and total body $\mathrm{Fe}$ and a decrease of TfRs compared with placebo $(P<0.05)$. Moreover, serum $\mathrm{Zn}$ increased significantly in group 2 compared with group $1(P<0.01)$ and placebo $(P<0.01)$.

Conclusion: Daily supplementation with $30 \mathrm{mg}$ de Fe plus $30 \mathrm{mg}$ de $\mathrm{Zn}$ for 3 mo improved significantly $\mathrm{Fe}$ and $\mathrm{Zn}$ status of women, compared with those who received placebo. The positive effect of Fe supplementation on Fe status is enhanced by combined $\mathrm{Zn}$ supplementation.

Funding: FONDECYT-1130075
3

EPINEPHRINE, DEXAMETHASONE, AND HYPERTONIC SALINE IN BRONCHIOLITIS, RANDOMIZED CLINICAL TRIAL

Rodríguez L L,2, Escobedo $\mathrm{Y}^{1,2}$, Wanzke $\mathrm{V}^{1}$, Murata $\mathrm{C}^{1,3}$

${ }^{1}$ Hospital General Naval de Alta Especialidad, México DF, México;

${ }^{2}$ Escuela Médico Naval, México DF, México;

${ }^{3}$ Instituto Nacional de Pediatría, México DF, México

Background: Bronchiolitis is the leading cause of lower respiratory tract infection and hospitalization in infants; however, no consensus has been established for its management.

Objective: We aimed to compare the efficacy of three different types of nebulized solution in the management of children with bronchiolitis:epinephrine + dexamethasone, hypertonic saline and normal saline.

Methods: Randomized, double blind clinical trial. Consecutive cases, aged 2-24 mo, with a clinical diagnosis of mild to moderate bronchiolitis were randomly assigned in a 1:1:1 ratio to one of three treatment regimen (nebulized). Group 1: single dose of $4 \mathrm{mg}$ dexamethasone plus two doses of $3 \mathrm{mg}$ epinephrine with a $20 \mathrm{~min}$ interval at first day, and a daily single dose of $4 \mathrm{mg}$ of dexamethasone from the second to fourth day, all of them nebulized; Group 2: three doses of nebulized $3 \%$ hypertonic saline, with $20 \mathrm{~min}$ intervals at first day, and daily single dose of the same solution from the second to fourth day; and Group 3: same schedule of treatment as the Group 2, but using $0.9 \%$ normal saline. Our primary outcomes were hospital admission rate and Respiratory Distress Assessment Instrument (RDAI) score, both evaluated at $7 \mathrm{~d}$ from the start of treatment.

Results: 42 patients were enrolled: 15 in group 1, 14 in group 2, and 13 in group 3; the hospital admission rate was $13.3,0$, and $46 \%$, respectively $(P=0.007)$; RDAI score for Group 3 was different from those of the other groups, but no difference was found between Groups 1 and 2 (TukeyKramer test for multiple comparisons: $P<0.05$ ).

Conclusion: Treatment with 3\% hypertonic saline lowers the rate of hospitalization and reduces breathlessness, at least to the same extent as treatment with Epinephrine plus Dexamethasone, in infants with mild to moderate bronchiolitis.

ClinicalTrials.gov: NCT01834820

\section{4}

RISK OF ACUTE KIDNEY INJURY IN DEHYDRATED CHILDREN WITH ACUTE GASTROENTERITIS EXPOSED TO IBUPROFEN

Thorel C, Ezquer M, Elmo ME, Molini A, Torrents M, Balestracci A

Hospital General de Niños Pedro de Elizalde, Buenos Aires, Argentina

Objective: To estimate if ibuprofen exposure is a risk factor for acute kidney injury (AKI) in dehydrated children with acute gastroenteritis (AGE), and whether the degree of dehydration influences on its development.

Methods: This is a case control-study, with prospective enrollment of patients. Data from children admitted with dehydration secondary to AGE from January to December 2013 were included. Only patients aged between $1 \mathrm{mo}$ and $18 \mathrm{y}$ with creatinine determined at admission were included. Children with chronic diseases predisposing to AKI or treated with others drugs were excluded.

Results: Patients $(n=105)$ were grouped as cases $(n=51)$ or controls $(n=54)$ depending on the presence of AKI or not, respectively. Children with AKI were younger $(0.74$ y vs. 1.62 y, $P=$ $0.0021)$, weighted less ( $7.75 \mathrm{k}$ vs. $10.5 \mathrm{k}, P=0.006)$, and were exposed to ibuprofen more frequently than controls $(38 / 51$ vs. $25 / 54, P=0.0032)$. Multivariate analysis, adjusted by dehydration degree, revealed ibuprofen exposure as an independent risk factor for AKI ( $P=0.00001$; OR: $2.86,95 \%$ CI: 2.08-3.94).

Conclusion: Ibuprofen exposure increased the risk for AKI in dehydrated children with AGE, independent of the degree of the dehydration. These findings reinforce that ibuprofen should be avoided in children with AGE since they are at risk of dehydration. 
5

HOW REAL ARE MATERNAL REPORTS OF EXCLUSIVE BREASTFEEDING?

Weisstaub G, Curi K, Gonzales M, Arroyo C, Cofre C, Anziani A, Salazar G

Instituto de Nutrición y Tecnología de los Alimentos (INTA), Universidad de Chile, Santiago, Chile Objective: To compare the report delivered by the mother, regarding exclusive breast-feeding as the only source of infant food intake, against a reference method.

Methods: Cross-sectional study including breastfed, both sexes, full-term infants, birth weight $>2,500 \mathrm{~g}$, with mothers without any breast pathology. We excluded children whose mothers had a history of smoking, hypertension, drug addiction or any severe pathology. The frequency of exclusive and predominant breastfeeding, reported by the mothers was compared to results obtained from saliva samples collected during $14 \mathrm{~d}$ (dose to the mother method), measured by mass spectrometry. Exclusive breastfeeding was assumed when the contribution of different liquids different from breast milk did not exceed $50 \mathrm{ml}$ (method error). The sensitivity and specificity of the mothers report was calculated. The study was approved by the Ethics Committee of INTA and mothers signed an informed consent.

Results: Fifty-two infants ( 20 females) were included in the study, age $3.3 \pm 0.3 \mathrm{mo}$. The average quantity of breast milk intake was $900 \pm 170 \mathrm{ml}$. The comparison between the standard method and that reported by the mothers had a sensitivity of $93.9 \%(31 / 33)$ and specificity of $57.9 \%(11 / 19)$ The reference method corroborated that a 79\% (31/39) of mothers gave exclusive breastfeeding and $11 / 13$ mothers, gave predominant breastfeeding.

Conclusion: Maternal reports overestimated the frequency of exclusive breastfeeding. The report used to assess the type of feeding given to the infants, had a high sensitivity and moderate specificity. Funding: Project RLA6071 (IAEA)

\section{6}

\section{A MORTALITY RISK MODEL FOR CHILDREN WITH CARDIAC SURGERY USING} BYPASS

Silva E, Herrera E, Delgado M, Perez R, Cordova E, Gudiel J, Chuquiure P, Huaman V, Davalos R, Barrientos A, Alamo C

Instituto Nacional de Salud del Niño (INSN), Lima, Perú

Background: Risk models play a key role in monitoring health care. In cardiac surgery, especially in children, monitoring the quality of care and auditing outcomes is mandatory. Unfortunately, there is not such a local model in Peru.

Objective: To develop an early mortality risk model for in children receiving cardiac surgery with cardiopulmonary bypass.

Methods: This is a single-institution, retrospective, cohort study, including children who received cardiac surgery with bypass, between January 2001 and December 2010. Reoperations wer excluded. Risk factors determined by the Society of Thoracic Surgeons (STS) were used, and early mortality was defined as occurring within $30 \mathrm{~d}$ after surgery. Binary logistic regression was used. Results: The global mortality of 1,028 patients was $15.8 \%$. The age $(\beta=-0.04)$, specific procedure ( $\beta=1.17$ ), urgency surgery $(\beta=0.69$ ), hemodynamic catheterization previous $(\beta=0.97)$, RACHS-1 ( $\beta=0.4-2.2)$, degree of heart failure ( $\beta=1.17-1.58)$ were the most important preoperative predictors of mortality. From the 1,028 patients included, $86.38 \%$ were correctly classified (AUC $=0.80$ $95 \%$ CI: $0.87-0.83$ ).

Conclusion: We developed an acceptable risk model for early mortality after CPB in children. This model may be useful for routinely monitoring outcomes, quality improvement, patient counseling shared decision making, and research.

\section{7}

IMPACT ASSESSMENT OF A DECISION RULE FOR USING ANTIBIOTICS IN CHILDREN VACCINATED AGAINST PNEUMOCOCCUS WITH PNEUMONIA

Ferrero F, Torres F, Dominguez P, Ossorio MF

Hospital General de Niños Pedro de Elizalde, Buenos Aires, Argentina

Background: Because ruling out bacterial etiology is difficult, initial management of children with pneumonia usually includes antibiotics. The Bacterial Pneumonia Score (BPS) is a clinical prediction rule that allows identifying children with pneumonia who do not require antibiotics, but its impact was evaluated before pneumococcal vaccine was included in the national vaccination schedule Objective: We assessed whether the use of the BPS for the initial management of patients with community-acquired pneumonia results in decreasing the use of antibiotics than under standard management of this condition, in children immunized against pneumococcus (PVC13).

Methods: This was a randomized, parallel-group, observer-blind, controlled clinical trial comparing the use of antibiotics in children aged 3-60 mo, immunized with pneumococcal vaccine, treated for pneumonia in an outpatient setting, according to two methods of initial management. Patients were assigned randomly to management according to the BPS (antibiotic indication with a BPS $\geq 4$ points) or routine management (antibiotic indication based on the institutional guidelines). We calculated the proportion of the use of antibiotics in each group and evaluated each patient's clinical outcome. Results: We included 65 patients ( 33 BPS and 32 controls) with a mean age of $17.5 \pm 10.8 \mathrm{mo}$. The use of antibiotics was significantly lower in the BPS group (27 vs. $65 \%$; OR: $0.19 ; 95 \%$ CI: $0.06-0.56$ $P<0.01)$. We observed an unfavorable outcome in seven patients $(10.7 \%)$, three in the BPS group and four in the control group (NS).

Conclusion: Antibiotics usage in children with pneumonia, previously vaccinated with PVC13, was significantly lower in the group managed according to the BPS compared to the conventionally treated group, without increasing the rate of treatment failure.

ClinicalTrials.gov: NCT01875731

\section{8}

IN VITRO ANTIBACTERIAL ACTIVITY OF NATURAL BIOACTIVE COMPOUNDS PER SE AND IN SYNERGY WITH CARBAPENEMS AGAINST KLEBSIELLA PNEUMONIAE

Cáceres Guido $\mathrm{P}^{1}$, Ojeda-Sana AM, Blanco $\mathrm{A}^{1}$, Macchi A ${ }^{1}$, Lopardo $\mathrm{H}^{1}$, Moreno $\mathrm{S}^{2}$

${ }^{1}$ Hospital de Pediatría Garrahan, Buenos Aires, Argentina;

${ }^{2}$ IIBBA-CONICET, Buenos Aires, Argentina
Background: The emergence of multiresistant bacteria has prompted research for new antibacterial strategies. A possible solution may be to combine existing antibiotics with antimicrobial natural compounds.

Objective: We study the effect of 1,8-cineol, a main constituent of Rosmarinus officinalis oil (rosemary), against nosocomial sensitive and resistant-Klebsiella pneumoniae strains and its synergism with carbapenems.

Methods: K. pneumoniae strains were treated with 1,8-cineol alone and in combination with ertape nem y meropenem using a bioassay in microplate (microdilution broth assay)

Results: 1,8 -cineole showed a MIC value of $20 \mu \mathrm{l} / \mathrm{ml}$ against a sensitive strain, while using $30 \mu \mathrm{l} / \mathrm{ml}$ inhibited $20-80 \%$ the growth of nosocomial $K$. pneumoniae strains resistant to meropenem, imipe nem, piperacillin/tazobactam, ampicillin/sulbactam, aztreonam, amoxicillin/clavulanic, ceftazidime, cefotaxime, cephalothin, cefepime, ciprofloxacin, gentamicin, amikacin (sensitive only to colistin and minocycline). The monoterpene at subinhibitory concentrations potentiated the action of ertapenem and meropenem (5-25 and $25-40 \%$, respectively). To clarify the potentiation effect, possible due to the lipophilic nature of 1,8-cineole, the fluorescent SYTOX-Green stain was used which only enter to cells with compromised plasma membranes. 1,8-cineole at 1/4 MIC value caused an increase in the fluorescence in both sensitive and resistant strains of near 50 and $30 \%$, respectively

Conclusion: 1,8-cineol acts synergistically with carbapenems, in vitro by increasing the cell mem brane permeability. Due to the emergence of carbapenem-resistant K. pneumoniae strains in the hospital environment, the 1,8-cineole in combination with carbapenems may be a therapeutic option for the treatment of health care-associated infections with emergent resistance.

\section{9}

“ZERO INFECTIONS” AT THE INSTITUTO NACIONAL DE SALUD DEL NIÑO IN LIMA, PERU

Nakachi G, Alvarado M, Santiago M, Fernández D, Marocho L, Shimabuku R

Instituto Nacional de Salud del Niño (INSN), Lima, Perú

Objective: To describe the decrease in nosocomial central line-associated bloodstream infections (CLABSI), after the implementation of a specific intervention in a Pediatric Intensive Care Unit.

Methods: Prospective cohort study, including all children, hospitalized in a Pediatric Intensive Care Unit, with a central venous catheter, from 2009 until 2012. Baseline data were obtained from 2009 to 2010 , and the program was developed from 2011 to 2012. The main outcome was the rate of catheter related bloodstream infection (CR-BSI) per 1,000 catheter days.

Results: Baseline data include 1,047 patients with CVC, followed during 9,303 catheter days, with an average annual CR-BSI rate was 6.03. During the project, 267 patients were followed, during 2,303 catheter days, showing an average annual CR-BSI rate of 1.7 .

Conclusion: The intervention allowed a significantly decrease in the CR-BSI rate in children hospitalized at Pediatric Intensive Care Unit.

\section{0}

\section{SPONTANEOUS BREATH TRIGGERING AT BIRTH: RESPIRATORY SUPPORT DURING} PRIMARY OR SECONDARY APNOEA?

Delgado C1, Shimabuku R1,2, Sánchez V1

${ }^{1}$ Instituto Nacional de Salud del Niño (INSN), Lima, Perú

${ }^{2}$ Universidad Nacional Mayor de San Marcos, Lima, Perú

Background: The standard procedure for respiratory support during neonatal resuscitation is Positive Pressure Ventilation (PPV) in the first $60 \mathrm{~s}$ of life. PPV is used in the assumption of secondary apnea, requires trained personnel and immediate availability of proper equipment. Unfortunately, in many countries access to resources is limited and other alternatives, more accessible than the bag and mask, are required.

Objective: To assess evidence to assume that basic neonatal resuscitation begins in primary apnea, and to determine whether this recommendation is based on the percentage of infants who begin their spontaneous breathing, receiving or not respiratory support.

Methods: Nonsystematic review on MEDLINE database using the terms "primary apnoea," "secondary apnoea," "gasping," "first breath," "birth asphyxia," and "basic neonatal resuscitation." Results: We reviewed the findings and selected 54 articles available in full text. Current recommendations state that it is preferable to consider secondary apnoea in those infants who require respiratory support. Less than $1 \%$ of newborn require advanced resuscitation. Respiratory support is effective in about $6-8$ of every 10 newborn that requires this help.

Conclusion: Because there is a high percentage of newborn babies who breath spontaneously even in the absence of respiratory support, it can be assume that the basic neonatal resuscitation is performed during primary apnoea.

\section{1}

\section{ADIPOSITY AND CARDIOVASCULAR RISK FACTORS IN CHILEAN SCHOOL} CHILDREN

Vasquez F, Corvalan C, Kain J, Uauy R

Instituto de Nutrición y Tecnología de los Alimentos (INTA), Universidad de Chile, Santiago, Chile

Objective: To assess the relationship between total and central obesity with indicators of cardiometabolic risk in 1,044 7-y-old Chilean children.

Methods: Anthropometric examination and total obesity index, such as: weight, body mass index (BMI), waist circumference, sum of four skinfold thicknesses, and body fat percentage. In centra obesity: waist circumference (WC), waist-hip ratio, waist-height ratio and trunk fat, were calculated. Two levels of overweight were defined (BAZ $>1 S D$ and $B A Z>2 S D$ ), as well as two levels of central obesity (WC $\geq 75$ th percentile and $W C \geq 90$ th percentile). We measured blood sample concentration of IGF-I, leptin, adiponectin, C-reactive protein, glucose, insulin, triglycerides, and total, LDL, and HDL cholesterol.

Results: The prevalence of overweight in both sexes was above $20 \%$. Obesity rate exceeded $14 \%$ and in boys and girls with high values of waist-hip ratio it was even higher (15\%). Girls had significantly higher total and trunk adiposity compared to boys $(P<0.0001)$. Boys had significantly higher values 
of total cholesterol $(P<0.001)$, LDL $(P=0.02)$, HDL $(P=0.01)$ and triglycerides $(P<0.001)$. In both sexes, the prevalence of high levels of glucose and HOMA-IR was less than $7 \%$. The correlation between indicators of total obesity was consistently strong and significant $(r \geq 0.81$ to 0.99 ; $P \leq 0.001)$, lower and significant in central obesity $(r \geq 0.20$ to $0.98 ; P \leq 0.001)$. Obese children of both sexes showed higher mean values of IGF-I and leptin $(P<0.001)$. Obese girls had higher mean values of insulin, glucose and similarly a higher prevalence of one, two and three or more cardiometabolic risk factors $(P<0.05)$

Conclusion: School-age children with obesity (total and central) had a higher prevalence of cardiometabolic alterations. There were strong correlations between anthropometric and total body fat and coefficients were lower with indicators of central fat distribution. These results support the need for early prevention and treatment of obesity in children.

\section{2}

HYPOGLYCEMIC AND/OR HYPOLIPEMIC EFFECT OF A FUNCTIONAL INGREDIENT IN RATS FED WITH A HIGH FAT DIET

Rojas L, Arredondo M

Instituto de Nutrición y Tecnología de los Alimentos (INTA), Universidad de Chile, Santiago, Chile

Background: Along with obesity, the prevalence of dyslipidemia and hyperglycemia has also increase, becoming a public health problem. The apple, grape and olive pomace are by-products of food industry rich in fiber and antioxidants.

Objective: The aim of this study was to determine the hypoglycemic and/or lipid lowering effect of a mixture made from apple, olive, and grape pomace, in rats fed with a high fat diet.

Methods: to evaluate the effects of consumption of the mixture, parameters related to glucose and lipids in plasma were determined. Additionally, total phenols, antioxidant activity and plasma Creactive protein was determined. We worked with four groups of five rats each: Controls (C), Control + mixture $(\mathrm{C}+\mathrm{IF})$, Obese $(\mathrm{Ob})$, and Obese + mixture $(\mathrm{Ob}+\mathrm{IF})$

Results: Consumption of the mixture had no effect on weight, body fat (as percentage) and satiety. However, there was a reduction in blood glucose and HOMA in C+IF rats, $143.7 \pm 13$ vs. $98.9 \pm 3.5 \mathrm{mg} / \mathrm{dl}$, and $4.0 \pm 0.6$ vs. $1.7 \pm 0.4$, respectively $(P<0.01)$. Regarding plasma lipids, the mixture had no effect on the levels of total cholesterol, LDL and HDL, but in plasma triglycerides of $\mathrm{Ob}+\mathrm{IF}$ rats $(114.1 \pm 9.4$ vs. $67.6 \pm 2.6 \mathrm{mg} / \mathrm{dl} ; P<0.01)$. No effects on antioxidant status were observed, but the levels of C-reactive protein.

Conclusion: The mixture induced a reduction in triglyceride levels, showing a potential tool as possible treatment for hypertriglyceridemia.

\section{3}

IDENTIFICATION OF BORDETELLA PERTUSSIS BY PCR IN INFANTS UNDER 1 Y OLD, HOSPITALIZED WITH PROBABLE PERTUSSIS IN FIVE HOSPITALS IN PERU, JANUARY 2010 to JULY 2012

Castillo $\mathrm{M}^{1}$, Rodriguez $\mathrm{E}^{1}$, del Aguila $\mathrm{O}^{2}$, Reyes $\mathrm{I}^{3}$, Bada $\mathrm{C}^{3}$, Petrozzi $\mathrm{V}^{4}$, del Valle $\mathrm{J}^{4,5}$, Cieza E ${ }^{1}$ Instituto Nacional de Salud del Niño, Jesús María, Peru;

${ }^{2}$ Hospital Edgardo Rebagliati, Jesús María, Peru;

${ }^{3}$ Hospital de Emergencias Pediátricas, Lima, Peru;

${ }^{4}$ Universidad de Ciencias Aplicadas, Lima, Peru;

${ }^{5}$ Laboratorio de Biología Molecular UPC-IIN, Lima, Peru;

${ }^{6}$ Diresa Cajamarca, Cajamarca, Peru

Background: Pertussis is a public health problem worldwide. Using high diagnostic accuracy tools is important in epidemiological surveillance.

Objective: To assess Bordetella pertussis diagnosis in children aged under $1 \mathrm{y}$, hospitalized fo whooping cough syndrome using PCR.

Methods: In all children nasopharyngeal (swab) samples were collected and processed, including culture and Polymerase Chain Reaction (PCR-BP)

Results: From 392 infants hospitalized with probable pertussis, 155 (40\%) were PCR-BP positive, and $9(2.3 \%)$ were culture positive. From 392 infants, 266 (68\%) were $\leq 3$. From 155 confirmed cases, parents (25\%) were the most frequent contacts. Paroxystic cough (87\%), respiratory distress (73\%), and cyanosis (56\%) were the more common symptoms. Apnea was more frequent in children $\leq 3$ mo old (20\%). The most common complications included pneumonia (27\%) and atelectasis $(10 \%)$ Ten $(2.6 \%)$ children died.

Conclusion: Using PCR, Bordetella pertussis infection was confirmed in $40 \%$ of hospitalized children with clinical suspicion. Most were younger $3 \mathrm{mo}$, and mothers were the more frequent contact.

\section{4}

ATOPIC SENSITIZATION TO AEROALLERGEN IN PATIENTS IN AN ALLERGY, ASTHMA, AND IMMUNOLOGY UNIT, PERU, 2013-2014

Córdova W, López M, Matos E, Galván C, Muñoz R

Unidad de Alergia Asma Inmunología, Instituto Nacional de Salud del Niño (INSN), Lima, Peru Background: Atopic condition prevalence in children is estimated to be $25-30 \%$. Despite according to the ISAAC study, Peru has intermediate prevalence (20.7-28.2\%), there is a lack of information regarding the aeroallergens sensitization profile.
Objective: To describe the aeroallergens sensitization profile in patients assisted in an allergy unit in Perú.

Methods: Cross-sectional study, including 300 patients aged 2 to $17 \mathrm{y}$, assisted in an allergy unit as outpatients.

Results: The frequency of atopic sensitization at least one allergen was $83 \%$. The most common allergens were Dermatophagoides farinae (64\%), D. pteronysinus (52\%) Blomia tropicalis (50\%), L. destructor (50\%), Chortoglypus arcuatus (39\%), Acarus siro (38\%), Tyrophagus putrescentiae (32\%). Sensitization to two allergens was $41 \%$, and to three allergens was $33 \%$. IgE level greater than $200 \mathrm{mg} / \mathrm{dl}$ were founded in $93 \%$, and absolute eosinophil count over 300 in $53 \%$.

Conclusion: Mites are the most prevalent allergens. Storage mites must be included in allergological testing panels in our region.

\section{5}

ARE INTERACTIVE VIDEOGAMES A THERAPEUTIC ALTERNATIVE IN THE MANAGEMENT OF CHILDHOOD OBESITY?

Rivero A, Soria R, Grandy G

Centro de Pediatría Albina R. de Patiño, Cochabamba, Bolivia

Background: Studies have shown that interactive video games could be an alternative to increase adhesion and improved integrated management of childhood obesity.

Objective: To describe the effect of the introduction of an interactive video game in fitness, anthropometry and adherence to treatment in obese children.

Methods: Randomized controlled trial including children 5-15 y of age with a diagnosis of obesity. Subjects were randomly assigned to perform aerobic exercise (controls) or play with Nintendo WII (cases). BMI, fitness and adherence to the procedure was assessed.

Results: We included 54 subjects, 27 cases, and 27 controls. Both groups showed significant decrease in BMI (controls: from 23.7 IQR \pm 3.7 to $22.8 \mathrm{IQR} \pm 3.7-; P=0.0001$ ) (cases: from $25.4 \mathrm{IQR}$ \pm 3.2 - to $24.2 \mathrm{IQR} \pm 2.9 ; P=0.0007)$. The assessment of the physical condition showed that the increase in heart rate was lower post-test in the evaluation at $30 \mathrm{~d}$, with a median of $30.6-22.7$ beats per minute beats per minute $(P=0.0001)$ in cases. Adherence was similar in both groups. Conclusion: Both types of physical activity showed similar results in the management of childhood obesity. Interactive video games could be an alternative in the management of childhood obesity.

\section{6}

SERUM 25-HYDROXYVITAMIN-D ASSOCIATIONS WITH BODY FAT AND INSULIN RESISTANCE IN PREPUBERTAL CHILEAN-CHILDREN Cediel G, Corvalán C, Aguirre C, López de Romaña D, Uauy R

Instituto de Nutrición y Tecnología de los Alimentos (INTA), Universidad de Chile, Santiago, Chile Objective: To evaluate the association between 25-hydroxivytamin-D (25-OHD,VD) and indicators of (i) total and central adiposity and (ii) insulin resistance (IR) in prepubertal Chilean-children. Methods: In a sample of 609 prepubertal-children ( $38 \%$ girls; mean-age $\sim 7$ y) who participate in the Growth-and-Obesity-Chilean-Cohort-Study (GOCS), we evaluated the association between serum-25-OHD (RIA-method-[Diasorin]) and indicators of (i) total-adiposity (z-score-body-mass-index-by-age (BAZ,WHO-2007), body-fat (BF\%) by skinfolds (GOCS Equation), bioimpedance (BIA-TANITA-418-BC), 3-components-model (3C-Model:BOP-PODD2O-dilution)), central-adiposity (waist-circumference (WC), waist-to-height-ratio $(\mathrm{WC} / \mathrm{H})$ skinfolds-ratio (trunk/limbs)), (ii) Insulin-resistance (IR:(Homeostatic Model Assessmentinsulin-resistance (HOMA-IR)), and insulin-sensitive (Quantitative Insulin Sensitive Check Index (QUICKI)) using standardized multiple regression models (range: 95\% CI) with standardized coefficients and ROC curves.

Results: Mean serum 25-OHD was $30.8 \pm 10.9 \mathrm{ng} / \mathrm{ml}, 55 \%$ had VD $<30 \mathrm{ng} / \mathrm{ml} ; 25 \%$ of children were overweight (BAZ $1-2$ SD) and $19 \%$ obese (BAZ $\geq 2$ SD). VD was inversely associated with total-adiposity (BMI-Z:-0.16 [-0.23,-0.09]; BF\%-BIA:-0.17 [-0.24,-0.09], BF\%-3C-Model:-0.21 [-0.32,-0.09]), central-adiposity (WC:-0.17 [-0.26,-0.09], WC/H:-0.12 $[-019,-0.05]$, skinfolds-ratio:-0.16 $[-0.28,-0.12])$, fasting-insulin $(-0.26[-0.35,-0.17])$ insulin-resistance (HOMA-IR:-0.29 $(-0.41,-0.17)$, and was directly associated to insulin sensitivity (QUICKI:0.17 [0.10,0.24]), after adjusting for sex, seasonality, age and also by adiposity in IR analysis. The serum 25-OHD cutoffs that better predicted obesity, high-total-adiposity (\%BF-Pc $\geq 75$ sample), central-adiposity (WC:Pc $\geq 75$ sample), hyperinsulinism ( $\geq 10 \mathrm{mU} / \mathrm{ml}$ ), insulin-resistance (HOMA-IR $>3.2 \mathrm{mU} / \mathrm{ml}$ ) and low-insulin-sensibility (QUICKI: $\leq$ P25 sample) were $28.3,29.7,29.6,27.6,28.5$, and $27.5 \mathrm{ng} / \mathrm{ml}$, respectively. Children who presented low serum-25-OHD $(<30 \mathrm{ng} / \mathrm{ml})$ showed higher probability of obesity (OR:2.6 [1.6,4.2]), high-total-adiposity (BF\%-BIA:OR:2.2 [1.5,3.2]), high-central-adiposity (CC:OR:1.9 [1.3,2.9]) IR (HOMA-IR:OR:2.3 [1.4,3.8]) and low-insulin-sensitivity (OR:2.4 [1.4,4.1]), than thei counterparts, after adjusting for covariates.

Conclusion: In prepubertal Chilean-children, serum 25-OHD was inversely associated to tota and central adiposity, as well as to IR indicators. The traditional cutoff value for VD insufficiency $(<30 \mathrm{ng} / \mathrm{ml})$ is also adequate to assess obesity and IR related metabolic risks associated to VD. Further studies are required to clarify the effect of the interaction between VD and adiposity on IR.

Funding: FONDECYT-1120326 y FONDECYT-1110085 